\title{
Proposta de UEPS sobre energia e sua lei de conservação
}

\author{
Proposed PMTU on energy and its conservation law \\ Propuesta de UEPS sobre energía y su ley de conservación
}

\author{
Mikaelly Rafaela Mariniak (mikaellyrafaela@gmail.com) \\ Universidade Federal do Paraná (UFPR). \\ Thaís Rafaela Hilger (hilger@ufpr.br) \\ Universidade Federal do Paraná (UFPR).
}

\begin{abstract}
Resumo: A partir da questão de pesquisa "como o conceito energia é apresentado em documentos normativos da Educação Básica?" e considerando a literatura já existente sobre o assunto, objetiva-se construir uma proposta didática que preencha as possíveis lacunas existentes. Para tanto, inicialmente os documentos normativos foram analisados e posteriormente a Unidade de Ensino Potencialmente Significativa foi construída à luz da Teoria da Aprendizagem Significativa. Sendo que o objetivo da proposta didática apresentada é facilitar a aprendizagem significativa do princípio de conservação de energia e de sua dependência com o conceito energia.
\end{abstract}

Palavras-chave: Ensino de Física; Aprendizagem significativa; Ensino Fundamental.

Abstract: Based on the research question "how is the concept of energy presented in normative documents of Basic Education?" and considering the existing literature on the subject, the objective is to build a didactic proposal that fills the possible existing gaps. For this purpose, initially the normative documents were analyzed and later the Potentially Meaningful Teaching Units (PMTU) was built in the light of the Theory of Significant Learning. The purpose of the didactic proposal presented is to facilitate the significant learning of the principle of energy conservation and its dependence on the concept of energy.

Keywords: Physics Teaching; Meaningful learning; Elementary School.

Resumen: A partir de la pregunta de investigación "¿cómo se presenta el concepto de energía en los documentos normativos de la Educación Básica?" y teniendo en cuenta la literatura existente sobre el tema, el objetivo es construir una propuesta didáctica que llene las posibles lagunas existentes. Para ello, inicialmente se analizaron los documentos normativos y más tarde se construyó la Unidad de Enseñanza Potencialmente Significativa (UEPS) a la luz de la Teoría del Aprendizaje Significativo. El propósito de la propuesta didáctica presentada es facilitar el aprendizaje significativo del principio de conservación de la energía y su dependencia del concepto de energia

Palabras-clave: Enseñanza de la Física; Aprendizaje significativo; Enseñanza básica.

Recebido em: 12/05/2021

Aceite em: 20/09/2021 


\section{INTRODUÇÃO}

Energia é um conceito interdisciplinar e indefinido e, embora esteja presente na linguagem cotidiana, a reflexão sobre sua natureza não é corriqueira. Não apenas na vida cotidiana a reflexão sobre a natureza da grandeza energia não é comum, mas também a Física atual não se preocupa com a sua definição (FEYNMAN, 2017). Outros conceitos fundamentais como tempo, temperatura e carga elétrica também fazem parte do senso comum, mesmo que sejam definidos apenas operacionalmente, por exemplo dizendo que tempo é aquilo que o cronômetro mede (MOREIRA, 1998). Assim, a comum definição de energia como a capacidade de realizar trabalho também é apenas operacional, o conceito é definido a partir de outros conceitos de maneira utilitária.

Outro conceito fundamental que parece cotidiano e, por consequência, não recebe devida atenção, é a simetria. Para a Física este conceito tem relação com leis de conservação e, estas, dizem que o valor de uma grandeza física permanece constante após o sistema físico passar por transformações. A lei de conservação mais conhecida é a da conservação de energia (MOREIRA, 2019). De modo que entender o conceito de energia passa necessariamente pela compreensão de que ela se transforma e se conserva. E é a partir desses processos que são nomeadas formas de energia (térmica, nuclear, elétrica, etc.) que "têm origem" em diferentes fontes de energia (aquecedor, usina nuclear, rede elétrica, etc.).

Uma vez que o conceito energia é interdisciplinar (WIRZBICKI; DEL PINO; PANSERA-DE-ARAÚJO, 2019; OSÓRIO; STOLL; MARTINS, 2019) e extremamente abrangente acredita-se que, na Educação Básica, ele pode ser abordado desde os anos iniciais do Ensino Fundamental (EF) até o Ensino Médio (EM), levando em consideração as adaptações necessárias para cada etapa escolar. Assim, a partir do questionamento sobre como o conceito energia é apresentado em documentos normativos da Educação Básica e considerando a literatura citada acima, objetiva-se construir uma proposta didática que preencha as possíveis lacunas existentes. Para tanto, inicialmente os documentos normativos serão analisados e, posteriormente, será apresentada a Teoria da Aprendizagem Significativa (na qual a proposta didática se insere) e, em seguida, a Unidade de Ensino Potencialmente Significativa (que constitui a proposta). Sendo que o objetivo da proposta didática apresentada é facilitar a 
aprendizagem significativa do Princípio de Conservação de Energia e de sua dependência com o conceito energia.

\section{DOCUMENTOS NORTEADORES}

A seguir será apresentada uma análise sobre a abordagem do conceito energia e a sua lei de conservação nos documentos oficiais de âmbito nacional e do estado do Paraná.

\section{Base Nacional Comum Curricular}

A Base Nacional Comum Curricular (BNCC) (BRASIL, 2017) é um documento normativo que pretende garantir um nível comum mínimo de aprendizagens a todos os estudantes brasileiros. O desenvolvimento adequado dessas aprendizagens deve garantir a evolução de competências gerais comuns a todas as etapas normatizadas pelo documento, são elas: Ensino Infantil (EI), Ensino Fundamental (EF) e Ensino Médio (EM). A fim de materializar as aprendizagens, o documento propõe a construção e aplicação de "avaliação formativa de processo ou de resultado que levem em conta os contextos e as condições de aprendizagem" (BRASIL, 2017, p.17). É importante destacar que a BNCC não é o próprio currículo, mas sim o guia das ações curriculares. A organização do EF na BNCC se dá por áreas do conhecimento, essas áreas possuem competências específicas e um ou mais componentes curriculares. A área de conhecimento Ciências da Natureza possui apenas o componente curricular Ciências.

As competências específicas são asseguradas pela divisão de cada componente curricular em unidades temáticas. Sendo que as unidades temáticas de Ciências são: Matéria e Energia, Vida e Evolução e Terra e Universo. Uma vez que este trabalho diz respeito ao conceito de energia, a unidade temática explorada é Matéria e Energia. De acordo com o documento:

A unidade temática Matéria e Energia contempla o estudo de materiais e suas transformações, fontes e tipos de energia utilizados na vida em geral, na perspectiva de construir conhecimento sobre a natureza da matéria e os diferentes usos da energia (BRASIL, 2017, p. 325).

Para cada unidade temática existem objetos de conhecimento específicos de cada ano escolar, assegurados por habilidades a serem desenvolvidas. 


\section{Referencial Curricular do Paraná}

O Referencial Curricular do Paraná (RCP) (PARANÁ, 2018) é o documento normativo estadual elaborado a partir da BNCC. Atualmente o documento é a referência para a revisão e reorganização dos currículos estaduais das instituições da Educação Básica. No momento, o documento diz respeito apenas ao EI e EF. "Embora a BNCC contemple toda a Educação Básica, o Ensino Médio não foi apresentado nesta fase da elaboração do documento por encontrar-se em discussão e análise" (PARANÁ, 2018, p. 9).

Entre os princípios orientadores do RCP está a "avaliação dentro de uma perspectiva formativa" (PARANÁ, 2018, p.11), de modo que o aspecto formativo sobrepõe o quantitativo e classificatório. Segundo o documento:

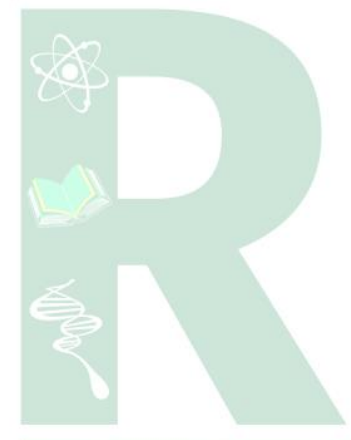

Assim, o ato de avaliar, em seu contexto escolar, se dá de maneira diagnóstica, na qual a situação de aprendizagem é analisada, tendo em vista a definição de encaminhamentos voltados para a apropriação do conhecimento; de forma contínua, pois acontece a todo o momento do processo de ensino do professor e da aprendizagem do estudante; e de maneira formativa, contribuindo para sua formação como sujeito crítico, situado como um ser histórico, cultural e social, enfatizando a importância do processo (PARANÁ, 2018, p. 27).

Uma vez que o RCP é fundamentado pela BNCC, as unidades temáticas do documento nacional são mantidas. O Referencial considera que os objetos de conhecimento relacionados às unidades temáticas podem ser trabalhados de acordo com características regionais, culturais, econômicas e socioambientais. Embora o RCP esteja de acordo com a BNCC, "alguns Objetos de Conhecimento e Objetivos de Aprendizagem foram complementados para subsidiar a compreensibilidade dos mesmos e outros, foram construídos visando ampliar a ação pedagógica docente em sala de aula" (PARANÁ, 2018, p. 307).

O documento foi elaborado em decorrência do caráter normativo da BNCC que torna obrigatória a elaboração ou reelaboração dos currículos e foi feito considerando a realidade educacional do Estado. A partir da finalização do Referencial (com aspecto legal e normativo), as propostas curriculares e Projetos Político Pedagógicos deveriam ser elaborados ou reelaborados em 2019. Assim, após orientação às escolas e formação 
continuada dos professores, os novos currículos deveriam ser efetivados em 2020

(PARANÁ, 2018).

\section{Currículo da Rede Estadual Paranaense}

A partir do RCP foi elaborado o Currículo da Rede Estadual Paranaense (CREP) (PARANÁ, 2020) que visa orientar a reelaboração dos currículos e propostas pedagógicos curriculares em função da adequação ao RCP e, por consequência, à BNCC. "O documento traz sugestões de conteúdos para cada componente curricular, em cada ano, indicando também possibilidades de distribuição na periodização do ano letivo." (PARANÁ, 2020, p. 2). Além disso, o CREP sistematiza os acréscimos feitos pelo Referencial à BNCC, criando para tanto um código alfanumérico que indica se a habilidade é a mesma habilidade da BNCC, se foi contextualizada, aprofundada, desdobrada ou se é referente a um novo objeto de conhecimento que não consta na BNCC.

Analisando os conteúdos indicados para os anos finais do EF, na Unidade Temática Matéria e Energia, pensando no conceito energia, é possível perceber que ele não aparece no $6^{\circ}$ ano. Tanto no $7^{\circ}$ quanto no $9^{\circ}$ ano o conceito aparece de forma tímida atrelado a outras ideias que se sobressaem.

No $7^{\circ}$ ano o conceito aparece relacionado à termodinâmica. $\mathrm{O}$ conceito de calor é abordado sem que exista diferenciação deste com o conceito de energia térmica. São abordados os processos de "propagação de calor". Por fim, o conteúdo Transformação de Energia aparece atrelado a máquinas térmicas. No $9^{\circ}$ ano o conceito energia não está presente, somente o conceito radiação. Portanto, só é possível dizer que energia aparece sob a perspectiva da natureza do conceito radiação.

Já no $8^{\circ}$ ano o conceito energia é abordado de forma explícita, conforme o Quadro 1. O CREP indica que estas habilidades sejam abordadas no $1^{\circ}$ trimestre do $8^{\circ}$ ano.

Quadro 1 - Conceito energia no $8^{\circ}$ ano do EF

\begin{tabular}{|c|l|l|}
\hline $\begin{array}{c}\text { Objeto de } \\
\text { conhecimento }\end{array}$ & \multicolumn{1}{|c|}{ Objetivo de aprendizagem } & \multicolumn{2}{|c|}{ Conteúdos } \\
\hline & $\begin{array}{l}\text { (PR.EF08CI01.s.8.01) Identificar e e } \\
\text { classificar diferentes fontes } \\
\text { (renováveis e não renováveis) e tipos } \\
\text { de energia utilizados em residências, }\end{array}$ & $\begin{array}{l}\text { Cinética; } 2 \text { Potencial Gravitacional; 3 - Energia Térmica; 4 - Energia } \\
\text { Energia: 1 - Energia }\end{array}$ \\
\hline
\end{tabular}

Recebido em: $12 / 05 / 2021$

Aceite em: 20/09/2021 


\begin{tabular}{|c|c|c|}
\hline \multirow{4}{*}{$\begin{array}{l}\text { Fontes e tipos de } \\
\text { energia; } \\
\text { Transformação } \\
\text { de energia; } \\
\text { Cálculo de } \\
\text { consumo de } \\
\text { Energia elétrica; } \\
\text { Circuitos } \\
\text { elétricos; } \\
\text { Uso consciente } \\
\text { de energia } \\
\text { elétrica }\end{array}$} & comunidades ou cidades. & 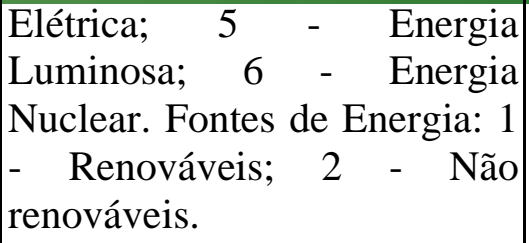 \\
\hline & $\begin{array}{l}\text { (PR.EF08CI03.s.8.03) Classificar } \\
\text { equipamentos elétricos residenciais } \\
\text { (chuveiro, ferro, lâmpadas, TV, rádio, } \\
\text { geladeira etc.) de acordo com o tipo de } \\
\text { transformação de energia (da energia } \\
\text { elétrica para a térmica, luminosa, } \\
\text { sonora e mecânica, por exemplo). }\end{array}$ & $\begin{array}{l}\text { Transformação de Energia; } \\
\text { Conservação de Energia }\end{array}$ \\
\hline & $\begin{array}{l}\text { (PR.EF08CI05.a.8.05 ) Propor ações } \\
\text { coletivas para otimizar o uso de } \\
\text { energia elétrica em sua escola e/ou } \\
\text { comunidade, com base na seleção de } \\
\text { equipamentos segundo critérios de } \\
\text { sustentabilidade (consumo de energia } \\
\text { e eficiência energética) e hábitos de } \\
\text { consumo responsável. }\end{array}$ & $\begin{array}{l}\text { Objetivo } \\
\text { procedime }\end{array}$ \\
\hline & $\begin{array}{l}\text { (PR.EF08CI06.s.8.06) Discutir e } \\
\text { avaliar usinas de geração de energia } \\
\text { elétrica (termelétricas, hidrelétricas, } \\
\text { eólicas etc.), suas semelhanças e } \\
\text { diferenças, seus impactos } \\
\text { socioambientais, e como essa energia } \\
\text { chega e é usada em sua cidade, } \\
\text { comunidade, casa ou escola }\end{array}$ & Geração de \\
\hline
\end{tabular}

Fonte: Adaptado de PARANÁ (2020).

A partir desta análise, considera-se que a etapa escolar adequada para a proposta didática a respeito do conceito energia e sua conservação é o $8^{\circ}$ ano, a fim de que esteja em consonância com os documentos norteadores nacionais e estaduais vigentes. A proposta se insere na Teoria da Aprendizagem Significativa (TAS) por se tratar de uma Unidade de Ensino Potencialmente Significativa.

\section{REFERENCIAL TEÓRICO}

A aprendizagem é dita significativa quando novos conhecimentos interagem de forma substancial e não arbitrária com conhecimentos prévios que possuem significados para o aprendiz, denominados subsunçores. A interação substancial implica em uma visão do conhecimento menos estática e mais fluida, de modo que a estrutura cognitiva 
de quem aprende passa a possuir papel fundamental na aquisição dos novos conhecimentos. O que é corroborado pela interação não arbitrária entre conhecimentos, já que a aprendizagem significativa não ocorre a menos que os novos conhecimentos interajam com os subsunçores e não com quaisquer conhecimentos prévios (AUSUBEL, 2003).

$\mathrm{Na}$ estrutura cognitiva de um sujeito os subsunçores se relacionam, se interrelacionam e organizam-se hierarquicamente, principalmente através de dois processos simultâneos: diferenciação progressiva (DP) e reconciliação integradora (RI) (MOREIRA, 2012). A DP reconhece que a organização dos conteúdos disciplinares são essencialmente hierárquica no que diz respeito à abstração, generalidade e inclusão. Já a RI confronta as diferenças e semelhanças entre os conhecimentos a fim de eliminar inconsistências (AUSUBEL, 2003).

Partindo da premissa de que não há ensino sem aprendizagem, Moreira (2011) sistematizou uma nova forma de organizar sequências didáticas a partir da TAS, a esta proposta o autor deu o nome de Unidades de Ensino Potencialmente Significativa (UEPS). O Quadro 2 sintetiza os passos para a construção de uma UEPS.

Quadro 2 - Aspectos sequenciais da UEPS

\begin{tabular}{|c|c|}
\hline $\begin{array}{l}\text { Aspecto } \\
\text { sequencial }\end{array}$ & Descrição \\
\hline Passo 1 & $\begin{array}{l}\text { Identificação, caracterização e contextualização do tópico a ser } \\
\text { abordado de acordo com a matéria de ensino. }\end{array}$ \\
\hline Passo 2 & $\begin{array}{l}\text { Criação de situações que levem os aprendizes a externalizarem seus } \\
\text { conhecimentos prévios em relação ao tópico. }\end{array}$ \\
\hline Passo 3 & $\begin{array}{l}\text { Sugerir situações problema introdutórias que levem em consideração os } \\
\text { conhecimentos prévios externalizados. }\end{array}$ \\
\hline Passo 4 & $\begin{array}{l}\text { Apresentar os conteúdos que serão trabalhados levando em } \\
\text { consideração a DP. }\end{array}$ \\
\hline Passo 5 & $\begin{array}{l}\text { Retomar os aspectos estruturantes dos conteúdos com maior grau de } \\
\text { complexidade do que feito anteriormente. }\end{array}$ \\
\hline Passo 6 & $\begin{array}{l}\text { Levando em consideração a DP, retomar os aspectos gerais dos } \\
\text { conteúdos privilegiando a RI. }\end{array}$ \\
\hline Passo 7 & $\begin{array}{l}\text { A avaliação da aprendizagem deve ser feita no decorrer da UEPS, mas } \\
\text { nesta etapa da proposta pode-se propor uma avaliação somativa e } \\
\text { individual que evidencie a captação de significados. }\end{array}$ \\
\hline Passo 8 & $\begin{array}{l}\text { Avaliar o êxito da UEPS a partir do desempenho dos aprendizes, ou } \\
\text { seja, se a avaliação fornecer indícios de aprendizagem significativa a } \\
\text { UEPS poderá ser considerada exitosa. }\end{array}$ \\
\hline
\end{tabular}

Recebido em: 12/05/2021

Aceite em: 20/09/2021 
Além dos aspectos sequenciais, as UEPS possuem aspectos transversais que sugerem que os questionamentos, diálogos, críticas e diversidade de materiais e estratégias de ensino devem ser privilegiados, o que facilita que a avaliação seja feita de forma contínua (MOREIRA, 2011).

\section{PROPOSTA DE UEPS}

A UEPS proposta neste trabalho foi elaborada para o $8^{\circ}$ ano do EF, supondo uma sala com cerca de 30 alunos e aproximadamente 9 aulas para a Unidade. O $8^{\circ}$ ano foi escolhido levando em consideração a literatura sobre o tema (ASSIS ; TEIXEIRA, 2003; BUCUSSI, 2006) e os atuais documentos normativos da Educação Básica (BRASIL, 2017; PARANÁ, 2018; 2020). Abordar o conceito no $8^{\circ}$ ano tem como objetivo facilitar o início da DP do princípio de conservação de energia para que também seja facilitada a RI quando o conceito for resgatado nos demais anos da escolarização.

O objetivo da UEPS proposta é facilitar a aprendizagem significativa do princípio de conservação de energia e de sua dependência com o conceito energia. Não há um momento preferencial para a aplicação da UEPS no $8^{\circ}$ ano, uma vez que, de acordo com os documentos normativos, é neste ano escolar que o conceito de energia começa a ser sistematizado. Assim, os conhecimentos prévios dos estudantes sobre energia não são vistos como pré-requisitos, mas sim como facilitadores ou dificultadores da aprendizagem. Mas, a fim de organizar o currículo, é sugerido pelo CREP (2020) que as discussões relativas à Matéria e Energia sejam feitas no $1^{\circ}$ trimestre desta etapa escolar. A seguir serão descritos os aspectos sequenciais da proposta.

\section{Verificação do conhecimento prévio (1 aula)}

Após a explicação do que é um mapa mental será solicitado que cada estudante elabore um a partir do conceito energia. Assim, os conhecimentos prévios serão externalizados e os possíveis subsunçores identificados. A organização dos elementos dos mapas reflete como as ideias a respeito da energia estão organizadas na estrutura cognitiva dos estudantes. A auto reflexão sobre esta organização na confecção do mapa 
pode preparar e predispor a estrutura cognitiva para ancorar novos conhecimentos. Os mapas serão recolhidos.

\section{Energia (2 aulas)}

Os alunos formarão pequenos grupos para buscar responder a questão "o que é energia?" (1 aula). As respostas serão obtidas a partir do conhecimento prévio que possuem, de modo que os significados que atribuem ao conceito serão negociados entre o pequeno grupo. O problema proposto envolve o tópico que a UEPS visa ensinar, mas neste momento o objetivo não é ensiná-lo, e sim ajudar os estudantes a organizarem sua estrutura cognitiva para aprendê-lo.

Após a discussão nos pequenos grupos será feita uma discussão geral sobre as respostas (1 aula). A discussão será guiada pelas respostas dos estudantes ao problema e pelos conhecimentos que externalizaram na construção dos mapas mentais, de modo que, possivelmente, incluirá suas concepções alternativas.

De acordo com a literatura (ASSIS; TEIXEIRA, 2003; BUCUSSI, 2006) as concepções alternativas mais comuns são energia: como algo material; como sinônimo de força e obrigatoriamente associada ao movimento. Assim, neste momento podem ser discutidas as possibilidades de adaptação destas concepções (se elas forem reveladas), por exemplo, a relação entre energia cinética e movimento.

O objetivo geral desta discussão é negociar os significados atribuídos pelos estudantes para que se chegue a conclusão que o conceito energia não pode ser definido facilmente mas que sabemos que ela existe a partir de sua transformação e conservação.

\section{Princípio de conservação de energia ( 2 aulas)}

Em uma aula expositiva-dialogada será discutido o princípio de conservação de energia. Também, será apresentado o conceito de sistema e a sua relação com o princípio. Serão retomadas as discussões a respeito da natureza do conceito de energia, realizadas nas aulas anteriores, a fim de facilitar a consolidação do conteúdo. Este momento visa destacar que: a conservação da energia é um princípio presente em diversas áreas da Física, que possui, também, caráter interdisciplinar e que a conservação é a característica mais importante da energia. Os aspectos mais gerais do conteúdo serão apresentados neste passo, de modo que a diferenciação progressiva será levada em consideração. 


\section{Formas de energia ( 3 aulas)}

Para dar continuidade a diferenciação progressiva do conteúdo os estudantes serão organizados em pequenos grupos, cada grupo terá como tema uma forma de energia. As formas de energia escolhidas são: térmica, sonora, elétrica, nuclear, cinética e potencial. Cada grupo deverá realizar uma pesquisa (1 aula) sobre sua forma de energia e posteriormente apresentá-la (2 aulas).

$\mathrm{Na}$ apresentação, os alunos deverão trazer as informações que julgarem necessárias sobre sua forma de energia, como suas características, sua fonte, sua rede de distribuição e discussões históricas que a envolvem. Como itens obrigatórios da apresentação os alunos deverão trazer uma notícia envolvendo seu tema e a discussão sobre quão cientificamente correta está a notícia.

Após as apresentações serão discutidas questões relativas à linguagem e a apropriação dos conceitos estudados na Unidade, como na expressão "estou sem energia hoje" e, possivelmente, nas notícias apresentadas. O objetivo desta etapa é evidenciar que as concepções utilizadas devem se adaptar ao contexto no qual estão inseridas.

\section{Relação entre formas de energia (1 aula)}

Os estudantes serão sorteados em duplas, sendo que cada integrante da dupla pesquisou sobre uma forma de energia diferente no passo anterior. Cada dupla deverá elaborar um exemplo que relacione os dois tipos de energia (cada um vindo de um integrante da dupla). Os exemplos elaborados serão compartilhados com o grande grupo e, posteriormente, serão recolhidos. O objetivo da atividade é facilitar a RI do conteúdo.

\section{Avaliação da aprendizagem}

A avaliação da aprendizagem será feita no decorrer da UEPS. Serão analisados indícios de aprendizagem significativa a partir da pesquisa, apresentação, discussões e tarefa solicitadas no desenvolvimento das aulas. A referência para a avaliação será o mapa mental elaborado na primeira aula, ou seja, o que os aprendizes já sabiam sobre o tema.

\section{Avaliação da UEPS}

Recebido em: $12 / 05 / 2021$

Aceite em: 20/09/2021 
A UEPS será considerada exitosa se facilitar a aprendizagem significativa do princípio de conservação de energia, bem como a compreensão que o aspecto mais relevante da energia é sua conservação. Deste modo, será avaliado não somente se os alunos aprenderam mas também se a aprendizagem foi facilitada pelas atividades propostas. Não é possível determinar com precisão se isso acontecerá, mas podem ser observados indícios do êxito das atividades, de acordo com avaliações somativas e formativas, a partir da interação dos estudantes ao realizá-las, de sua adequação ao objetivo da UEPS e da consideração da DP e RI na construção das atividades desenvolvidas.

\section{CONSIDERAÇÕES FINAIS}

A aprendizagem mecânica, acrítica e descontextualizada, infelizmente, é a que predomina no ambiente escolar. A UEPS descrita neste artigo visa incentivar a construção e, principalmente, a implementação de propostas que rompam com o modelo tradicional de ensino no qual os aprendizes são sujeitos passivos e os conteúdos estudados servem somente para "passar de ano" (MOREIRA, 2012).

Esta proposta partiu da premissa de que existem conteúdos mais fundamentais do que outros e que estes devem ser privilegiados na construção de um currículo escolar. Diante disso, considerou-se que energia é um dos conceitos mais essenciais para a Física e para a Ciência de modo geral. Assim, não existe uma idade certa e rigidamente predeterminada para introduzir este conceito no ambiente escolar, desde que sejam feitas as adaptações necessárias para cada etapa escolar e cada contexto, o que é incentivado pelos documentos normativos já que energia está presente desde o Ensino Fundamental.

\section{REFERÊNCIAS}

ASSIS, A.; TEIXEIRA, O. P. B. Algumas considerações sobre o ensino e a aprendizagem do conceito de energia. Revista Ciência e Educação, v. 9, n. 1, p. 41-52, 2003.

AUSUBEL, D. P. Aquisição e retenção do conhecimento: uma perspectiva cognitiva. Lisboa: Plátano Edições Técnicas, 2003.

BRASIL. Ministério da Educação. Base Nacional Comum Curricular: Educação é a base. Disponível em:<http://basenacionalcomum.mec.gov.br/images/BNCC_EI_EF_110518_versaofinal _site.pdf $>$.Acesso em: 16 mai. 2020. 
BUCUSSI, A. A. Introdução ao conceito de energia. Textos de apoio ao professor de física, v. 17, n.3, 2006.

FEYNMAN, R. F. Física em 12 lições: fáceis e não tão fáceis. (2a ed.). Rio de Janeiro: Nova Fronteira, 2017.

MOREIRA, M. A. CABALlERO, M. C. RODRÍGUEZ, M. L. Aprendizagem significativa: um conceito subjacente. In: Encuentro Internacional sobre el Aprendizaje Significativo. Burgos, 1997.

MOREIRA, M. A. O conceito de simetria na Física. Revista do Professor de Física, v. 3, n. 2, p. 1-8, 2019.

2012.

O que é afinal aprendizagem significativa? Qurriculum, La Laguna, Espanha,

Unidades de enseñanza potencialmente significativas. Aprendizagem

Significativa em Revista, v. 1, n. 2, p. 43-63, 2011.

OSÓRIO, T. R.; STOLL, V. G.; MARTINS, M. M. Investigação na Formação Inicial: concepções sobre as TIC e a Energia no Curso de Licenciatura em Ciências da Natureza. Revista Insignare Scientia, v. 2, n. 2, p. 22-36, 2019.

PARANÁ. Currículo da rede estadual paranaense: Ciências. [2020]. Disponível em: http://www.educadores.diaadia.pr.gov.br/modules/conteudo/conteudo.php?conteudo $=16$ 69. Acesso em: 12 de abr. de 2021.

Referencial Curricular do Paraná: Princípios, direitos e orientações. [2018]. http://www.educadores.diaadia.pr.gov.br/arquivos/File/bncc/2018/referencial_curricular _parana_cee.pdf. Acesso em: 12 de abr. de 2021.

WIRZBICKI, S. M.; DEL PINO, J. C.; PANSERA-DE-ARAÚJO, M. C. O Conceito Energia nas Interações entre Professores e Estudantes Mediadas pelos Livros Didáticos de Biologia. Revista Insignare Scientia, v. 2, n. 1, p. 138-150, 2019. 